\title{
Direct Evidence to Support the Immunosurveillance Concept in a Human Regressive Melanoma
}

\author{
Andreas Mackensen, Guislaine Carcelain, Sophie Viel, Marie-Cecile Raynal, " Helene Michalaki, * \\ Frederic Triebel, Jacques Bosq, ${ }^{\ddagger}$ and Thierry Hercend \\ Laboratoire d'Hemato-Immunologie, INSERM U333, * Laboratoire Mixte Institut Gustave Roussy/Roussel Uclaf, \\ and ${ }^{\ddagger}$ Departement d'Histopathologie, Institut Gustave Roussy, F-94805 Villejuif Cedex, France
}

\begin{abstract}
The concept of immunosurveillance against cancer has been an extensively debated question over the last decades. Multiple indirect arguments have supported the view that the immune system may control, at least in certain cases, malignant cell growth while direct demonstration is still lacking in the human. In an attempt to address this issue, we have selected a study model, namely spontaneously regressive melanoma. In previous series of experiments, the variability of $T$ cell receptors (TCRs) in the lymphocytes infiltrating a regressive tumor lesion was investigated. Results demonstrated that clonal $\mathbf{T}$ cell populations, precisely defined through their V-D-J junctional sequences, were amplified in situ. One clone was predominant, expressing the $V \beta 16$ variable gene segment. A specific antiV $\beta 16$ TCR mAb was generated here to purify and functionally characterize the corresponding cells. A tumor-infiltrating lymphocyte-derived $\mathrm{V} \beta 16^{+} \mathrm{T}$ cell line was developed using this reagent. These in vitro cultured cells were found to express the in vivo predominant TCR sequence exclusively and to display an HLA-B14-restricted cytotoxic activity against the autologous tumor cells. Immunohistochemical experiments, performed with the anti-V $\beta 16 \mathrm{mAb}$, showed that the corresponding CTLs are present in the tumor area, some of them being closely opposed to the melanoma cells. Together, these studies demonstrate the existence of a local adaptive immune response clinically associated to tumor regression, thus strongly supporting the validity of the immunosurveillance concept in certain human tumors. (J. Clin. Invest. 1994.93:1397-1402.) Key words: melanoma $\bullet$ lymphocytes $\bullet$ tumor infiltrating $\bullet$ neoplasm regression • spontaneous
\end{abstract}

\section{Introduction}

Previously, we have studied a case of melanoma displaying the well-agreed clinical and histological characteristics of "spontaneous" tumor regression (1). It was initially shown by immunohistochemical experiments that T cell receptor (TCR) ${ }^{1} \alpha /$ $\beta^{+}$lymphocytic infiltrates were present in the regressive lesion

Address correspondence to Dr. Guislaine Carcelain, INSERM U255, Institut Curie, 26, rue d'Ulm, F-75231 Paris Cedex 05, France.

Dr. Mackensen's present address is Department of Oncology, University of Freiburg, 79106 Freiburg, Germany.

Received for publication 31 August 1993 and in revised form 8 December 1993.

1. Abbreviations used in this paper: TCR, T cell receptor; TIL, tumorinfiltrating lymphocytes.

J. Clin. Invest.

(c) The American Society for Clinical Investigation, Inc.

0021-9738/94/04/1397/06 \$2.00

Volume 93, April 1994, 1397-1402
(1). PCR-based molecular analysis of the TCR $\beta$ chains expressed by the tumor-infiltrating lymphocytes (TIL) was performed directly in situ demonstrating the overrepresentation of a limited number of $\mathrm{V} \beta$ gene segments, in particular $\mathrm{V} \beta 16$ (22 vs. $4 \%$ in PBL). Extensive sequence analysis of the V-D-J junctional regions of the $\mathrm{V} \beta 16$ transcripts expressed in situ showed that $84 \%$ of them corresponded to a unique mRNA, while the control V $\beta 16$ sequences from autologous PBL were polyclonal (1). These experiments demonstrated that clonal T cell populations were indeed selected and amplified at the tumor site, but were not informative regarding the function of the corresponding lymphocytes. It was subsequently attempted to characterize the $\mathrm{V} \beta 16^{+} \mathrm{T}$ cells through in vitro generation of cell lines and clones derived from the TIL. This attempt failed although we could characterize other $T$ cell clones overgrowing in the culture while being less dominant in vivo (2). Note that one of them, expressing the $\mathrm{V} \beta 13$ gene segment, was shown to display high levels of cytotoxicity against the autologous tumor cells (2). Why the cell type most represented (i.e., $\mathrm{V} \beta 16^{+}$) in vivo displayed a relatively poor capacity of expansion in vitro remains unclear.

In an attempt to circumvent this difficulty and characterize the $\mathrm{V} \beta 16$ cells, we have generated here a specific anti-V $\beta 16$ TCR mAb to allow positive selection and specific proliferative triggering of the corresponding cells. Using this approach, we could demonstrate that the $\mathrm{V} \beta 16^{+}$lymphocytes represent a unique HLA class I-restricted cytotoxic T cell (CTL) strongly active against the autologous tumor. In addition, immunohistochemical analysis with the anti-V $\beta 16 \mathrm{mAb}$ provide evidence that the corresponding clone is indeed present in the regressive melanoma lesion. Together, the results demonstrate that $\mathrm{V} \beta 16^{+} \mathrm{T}$ cells, found to be predominant in situ, display a tumor-directed cytotoxic effector function in the clinical context of cancer regression.

\section{Methods}

Patient. The patient under study was a 65 -yr-old woman suffering from a primary malignant melanoma with clinical and histological signs of tumor regression, as described previously (1).

TIL cultures. Generation of the TIL-derived T cell line from the regressive melanoma lesion was described previously (2). Cells were expanded by plating $5 \times 10^{3}$ cells per well in 96-well, V-shaped microtiter plates (Nunc, Roskilde, Denmark) in the presence of irradiated autologous EBV-B cells ( $60 \mathrm{~Gy}, 1.5 \times 10^{4}$ cells/well ) plus allogeneic PBL ( $35 \mathrm{~Gy}, 7 \times 10^{4}$ cells/well) and in the presence of $100 \mathrm{U} / \mathrm{ml}$ human recombinant IL-2 (Roussel-Uclaf, Romainville, France), and $3 \% \mathrm{~T}$ cell growth factor.

Tumor cell lines. Generation and expansion of the autologous melanoma cell line (M10) has been described previously (2). Analysis of the HLA phenotype of this cell line revealed the same specificities (HLA-A3, -A 10, -B14, and -B35) found on autologous PBL (data not shown). Tumor lines were maintained in monolayer and passaged 


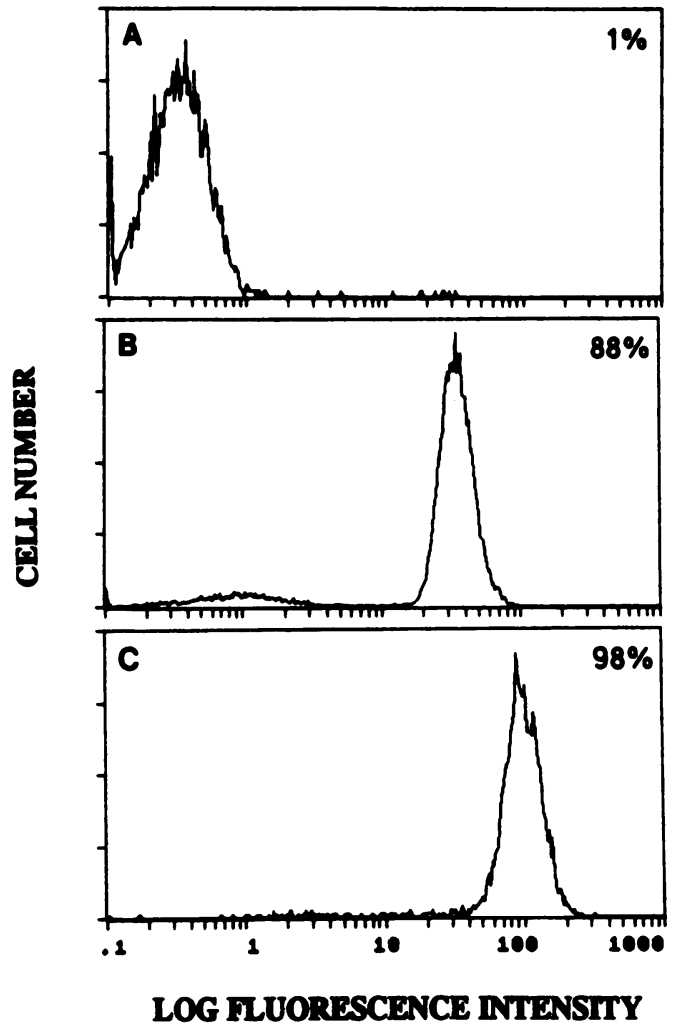

Figure 1. Flow cytometric analysis of the $\mathrm{V} \beta 16^{+}$cells stained with anti-V $\beta 16 \mathrm{mAb}$ before $(A)$, after first $(B)$, and after second $(C)$ round of immunomagnetic separation. Histograms represent the number of cells versus intensity of fluorescence on a logarithmic scale. The percentage represents the amount of $\mathrm{V} \beta 16^{+}$cells compared with the control mAb NKTa.

with $0.05 \%$ trypsin. Additional tumor cell lines maintained in culture include two human allogeneic melanoma cell lines (M11, M12). Immunofluorescence analysis with antibodies to HLA-A3, -A10, -B14, and -B35 demonstrated that these allogeneic cell lines do not share an HLA class I antigen with the M10 autologous cells (data not shown). $\mathrm{K} 562$ is a human myeloid leukemia line commonly used as a target for natural killer cells. LAZ 388 is an EBV-transformed B cell line described previously (2). LCL is an EBV-transformed B cell line derived from autologous PBL.

$m A b s$, serological reagents, and phenotypic analysis. 145-2C11 (2C11) recognizes the $\epsilon$ chain of the murine CD3 molecule (3). BMA 031, kindly provided by Dr. R. Kurrle (Behring Company, Marburg, Germany), reacts with a monomorphic determinant of TCR $\alpha / \beta$ receptor (4). Anti-TCR- $\delta 1 \mathrm{mAb}$ (T Cell Science, Cambridge, MA) recog- nizes a constant epitope of the human TCR- $\delta$ chain (5). OKT3, OKT4, and OKT8 (Ortho Diagnostics Systems, Inc., Westwood, MA) react with the $\mathrm{CD} 3, \mathrm{CD} 4$, and $\mathrm{CD} 8$ proteins, respectively. W6/32 (6) $\mathrm{mAb}$ recognizes a monomorphic determinant of HLA class I gene products. Anti-NKTa mAb recognizes an infrequent TCR $\alpha / \beta$ clonotypic determinant (7). Each mAb was used at a saturating concentration predetermined by titration curves on positive cloned cell lines.

Human HLA-reactive pregnancy sera (anti-A3, anti-A10, antiB14, anti-B35) were kindly provided by Dr. C. Raffoux (Hopital Saint Louis, Paris, France). Single- and two-color indirect immunofluorescence analyses were performed using an Elite flow cytometer (Coulter Electronics Inc., Hialeah, FL) as described previously (7).

Generation of $\mathrm{mAb}$ against human V $\beta 16$ gene segment. Production of a V $\beta 16$ transfectant cell line was performed as described by Romagné et al. (8). Briefly, cDNA was prepared from PBL and submitted to PCR amplification using a $C \beta$-specific antisense primer (8) and a $\mathrm{V} \beta 16$-specific sense primer designed to introduce an EcoRI restriction site as well as the CCACC Kozak sequence (9) in front of the AUG codon (5'-GCGAATTCCACCATGGTTTCCAGGCTTCTCAGTT$\left.3^{\prime}\right)$. Amplified products were cloned into the $\mathrm{pBSmC} \beta 215$ vector (8). After subsequent XhoI-NotI double restriction digest the $\mathrm{hV} \beta 16-\mathrm{mC} \beta$ fragment was subcloned into the NT expression vector (F. Romagné, unpublished results) corresponding to pSV2neo with insertion of the $\mathrm{SR} \alpha$ promoter (10). The recombinant construct (V16NT) was then electroporated into DOIS- 19 cells (11) together with the pCA 258 plasmid for high yield coexpression of the CD3zeta chain (12). After selection for G418 resistance TCR-positive cells were subsequently identified by flow cytometry as described (8).

BIOZZI mice were immunized with transfectants expressing a chimeric TCR $\beta$ chain that includes the hV $\beta 16$ segment (13). Spleen cells from the immunized animals were then fused to the NS-1 nonsecreting myeloma (14). Supernatants of growing hybridoma cells were screened for the ability to produce an anti-V $\beta 16 \mathrm{mAb}$ as described by Romagné et al. (8).

Purification of $V \beta 16^{+}$cells from the TIL-derived T cell line. $\mathrm{V} \beta 16^{+}$ cells were purified from the TIL cell line by positive selection with magnetic beads (Dynabeads; Dynal, Oslo, Norway). For separation, cells were stained with anti-V $\beta 16 \mathrm{mAb}(1: 400)$, a saturating concentration predetermined by titration curves on a $\mathrm{V} \beta 16^{+}$IL-2-dependent cell line, and incubated with Dynabeads M-450 sheep anti-mouse IgG (Dynal) with a ratio of three beads for one estimated positive cell. Positive cells were then separated using a magnet.

Immunohistochemical staining procedures. Anti- $\mathrm{V} \beta 16 \mathrm{mAb}$ was used at 1:50 dilution selected after a series of preliminary experiments performed to assess the optimal experimental conditions. As controls we have used several mAbs such as pan-TCR $\alpha / \beta$ reagent (BMA 031 $\mathrm{mAb}$ ), pan-TCR $\gamma / \delta$ reagent (anti-TCR $\delta 1 \mathrm{mAb}$ ), and other mAbs against $\mathrm{T}$ cell-associated antigens (CD3, CD4, CD8). A polyclonal biotinylated sheep antibody to mouse Ig (reactive with all mouse isotypes) and a streptavidin-biotinylated peroxidase complex (all obtained from Dako, Glostrup, Denmark) served as a detection system for the primary antibody. 3-Amino-9-ethylcarbazole (Dako) was used

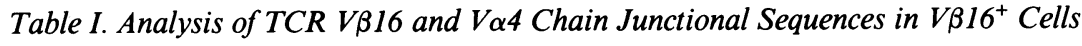

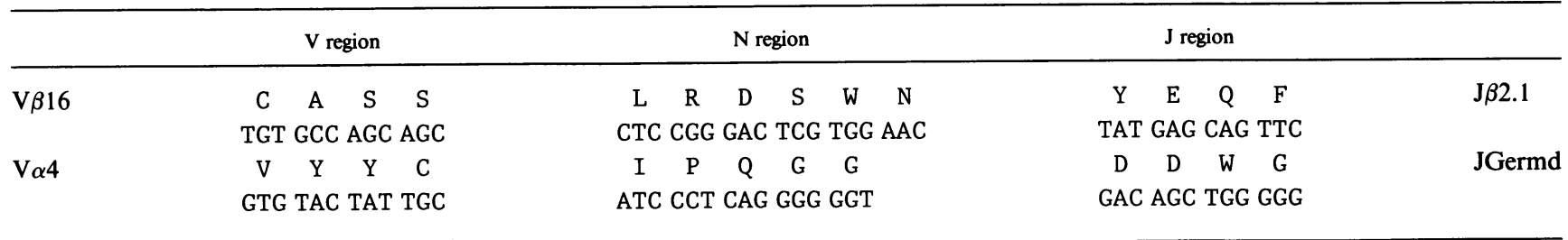

cDNA from the $\mathrm{V} f 16^{+}$cell line was amplified with a $\mathrm{V} \alpha 4$ - or $\mathrm{V} \beta 16$-specific $5^{\prime}$ oligonucleotide primer, paired with the corresponding $\mathrm{C} \alpha$ or $C \beta$-specific $3^{\prime}$ primer. PCR-generated V $\beta 16$ and $\mathrm{V} \alpha 4$ TCR chain fragments were cloned into a EcoRV-cut ddT-tailed pBS-SK ${ }^{+}$vector. Double-stranded plasmid DNAs were sequenced directly with the Sequenase kit (United States Biochem. Corp.). A translated amino acid sequence is shown above each corresponding nucleotide sequence. 


\section{\% SPECIFIC LYSIS}

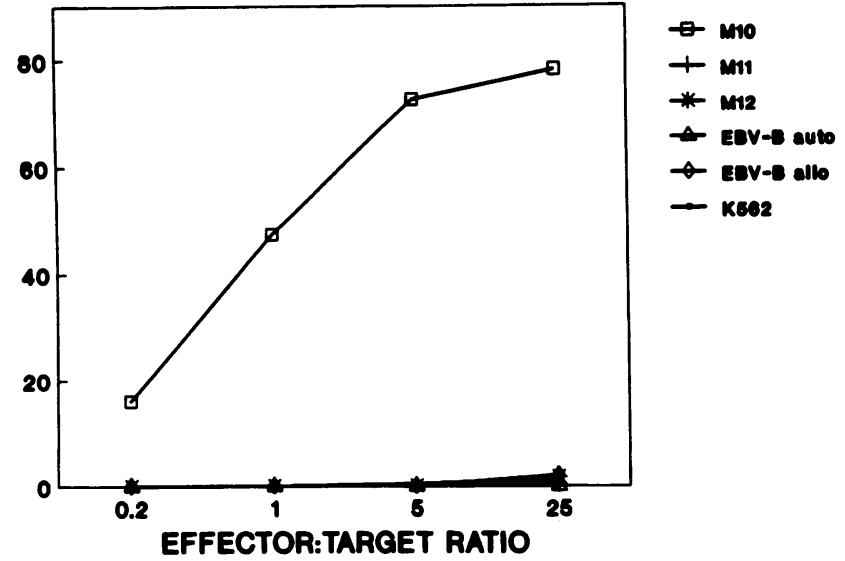

Figure 2. Specificity of $\mathrm{V} \beta 16^{+}$cells directed against autologous melanoma cells. Cytotoxicity was determined in a 4-h ${ }^{51} \mathrm{Cr}$ release assay on autologous (M10) and allogeneic (M11, M12) melanoma cell lines, autologous and allogeneic EBV-transformed B cells, and the NK target K562, as described (2). Values represent means of triplicates $(\mathrm{SD}<5 \%)$ at $\mathrm{E} / \mathrm{T}$ ratios of $25: 1,5: 1,1: 1$, and $0.2: 1$.

as substrate for the enzyme; the peroxidase reaction resulted in an intense red precipitate.

Cytotoxicity assays. The cytotoxic activity of the $\mathrm{V} \beta 16^{+}$TIL cell lines was measured by a conventional $4-\mathrm{h}^{51} \mathrm{Cr}$ release assay using triplicate cultures in V-bottomed plates. E/T ratios were 25:1, 5:1, 1:1, $0.2: 1$, and $0.04: 1$ on 2,000 target cells per well. The percentage of specific cytotoxicity was calculated conventionally; SDs were $<5 \%$.

Functional effects of the antibodies and antisera, either on effector cells (OKT3, OKT4, OKT8, BMA031, TA-37) or on target cells (W6/ 32 , antisera anti HLA-A3, anti HLA-A10, anti HLA-B14, anti HLAB35), were tested by incubating each of them for $2 \mathrm{~h}$ at $37^{\circ} \mathrm{C}$ before the assay at the predetermined saturating concentration. The percentage of inhibition of lysis was calculated as:

$1-\frac{\% \text { specific lysis in mAb/antisera-treated wells }}{\% \text { specific lysis in control wells }} \times 100$.

Synthesis of the first strand of $c D N A$. Total RNA was prepared from the $\mathrm{V} \beta 16^{+}$cell line using a single-step guanidinium isothiocyanatephenolchloroform extraction method (15). First-strand cDNA was synthetized with oligodeoxythymidine (oligo-dT) priming and reverse transcriptase.

Molecular analysis of TCR $V$ gene segments using PCR. The procedure used to analyze TCR $\mathrm{V} \alpha$ and $\mathrm{V} \beta$ gene segment expression has been described previously (16). Briefly, these TCR transcripts cDNA were amplified in a 30-cycle PCR, using the 29 different $\mathrm{V} \alpha$ and $24 \mathrm{~V} \beta$ 5 '-oligonucleotide primers ( $\mathrm{V} \alpha 1-\mathrm{w} 29 / \mathrm{V} \beta 1-\mathrm{w} 24)$, each of them paired with the corresponding $\mathrm{C} \alpha$ - or $\mathrm{C} \beta$-specific 3' primer. Positive $\alpha$ and $\beta$ controls consisted of constant region amplifications ( 180 and $190 \mathrm{bp}$, respectively) and negative controls were performed without cDNA (16). The amplified products were detected by Southern blot analysis using a $\mathrm{C} \alpha$ or $\mathrm{C} \beta$ oligonucleotide probe.

Cloning and sequencing of $V \beta 16$ and $V \alpha 4$ transcripts. The technique used for cloning and sequencing of $\mathrm{V} \alpha$ and $\mathrm{V} \beta$ transcripts has been described previously (1). Briefly, the primers for the cloning of $\mathrm{V} \beta 16$ sequences were 5'-GCCTGCAGAACTGGAGGATTCTGG-3' in the $V$ region and 5'-GGTGTGGGAGAATTCTGCTTCTGA-3' in the $C \beta$ region. For amplification of $\mathrm{V} \alpha 4$ sequences the primers were 5'-TTGGTATCGACAGCTTCACTCCCA-3' for V region and 5'GTTGCTCCAGGCCGCGGCACTGTT-3' for $\mathrm{C} \alpha$ region. The amplifications were performed in 1 round of 30 cycles. After ethanol precipitation, the amplified products were separated on a $2 \%$ agarose gel and purified by absorption on glass beads (Gene Clean; BIO 101, Inc., La
Jolla, CA). The material was directly ligated into a EcoRV-cut ddT-

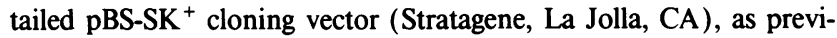
ously described (17). Competent XL-1 blue Escherichia coli strains (Stratagene) were transformed and plated for blue/white color selection on media containing $\mathrm{X}-\mathrm{Gal}$. The white colonies were screened by the dot blot technique and a $\mathrm{C} \beta$ or $\mathrm{C} \alpha$ oligonucleotide probe. Plasmid DNA was extracted from positive colonies and sequenced by the dideoxy-chain termination procedure (Sequenase 2.0; United States Biochem. Corp., Cleveland, $\mathrm{OH}$ )

\section{Results}

Generation of a $\mathrm{VBI}^{+}$cell line derived from the TIL population. A plasmid, containing the $\mathrm{V} \beta 16$ sequence expressed predominantly in the TIL in vivo ( 1 ), was linked to the murine $C \beta$ gene and electroporated into DOIS 19 cells, a TCR- $\beta^{-}$variant of the mouse T cell hybridoma DO-11.10.7 $(8,11)$. Mice were immunized with a stable tranfectant expressing the corresponding TCR chain. Hybridomas were screened by flow cytometry using transfected vs. nontransfected cells. The specificity of one of them (TA-37) was established according to a series
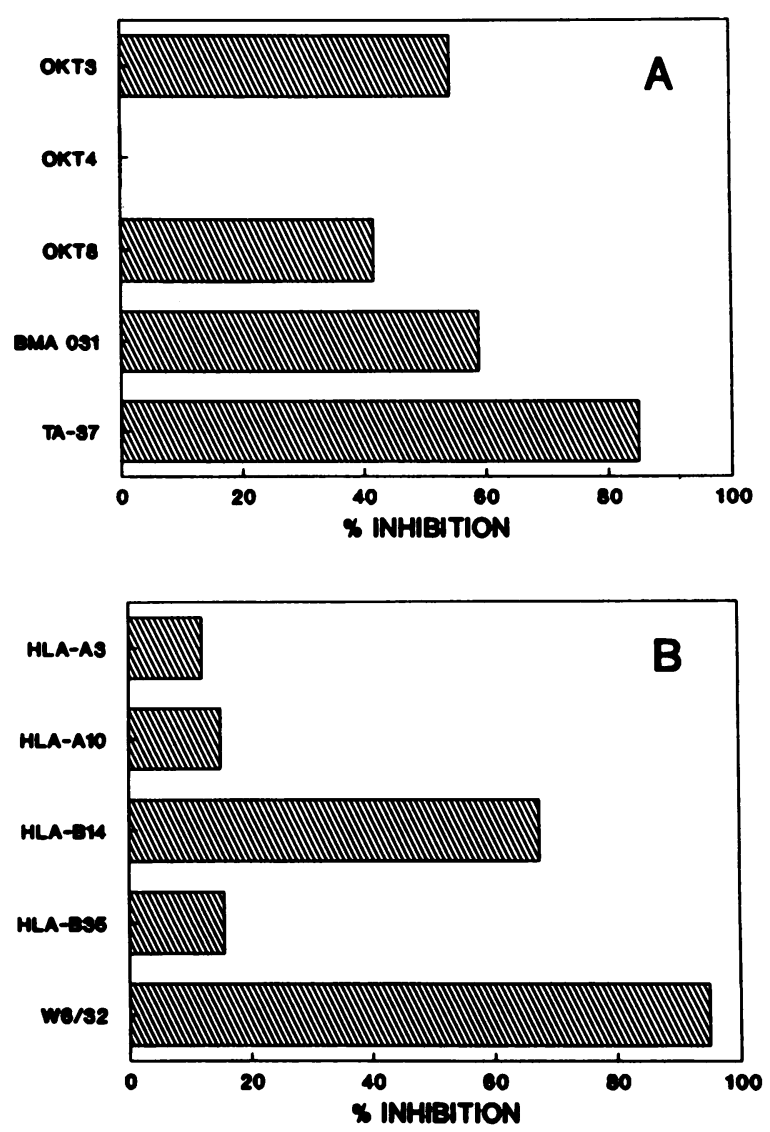

Figure 3. Inhibition of specific cytotoxicity of $\mathrm{V} \beta 16^{+}$cells towards autologous melanoma cells by monoclonal antibodies and antisera. $(A)$ Effector cells were preincubated with each of the antibodies (OKT3, anti-CD3; OKT4, anti-CD4; OKT8, anti-CD8; BMA031, anti-TCR $\alpha / \beta$ monomorphic; TA-37, anti-V $\beta 16)$ for $2 \mathrm{~h}$ before the cytotoxicity assay. (B) Target cells (M10) were preincubated either with $\mathrm{mAb}$ W6/32 (anti-HLA class I monomorphic) or with polyclonal human antisera to HLA-A3, -A10,-B14, -B35 at 1:2 dilutions for $2 \mathrm{~h}$ before the addition of the effectors. Cytotoxicity was determined in a 4- ${ }^{51} \mathrm{Cr}$ release assay at an $\mathrm{E} / \mathrm{T}$ ratio of $1: 1$, and the percentage of inhibition was calculated as described before (2). 

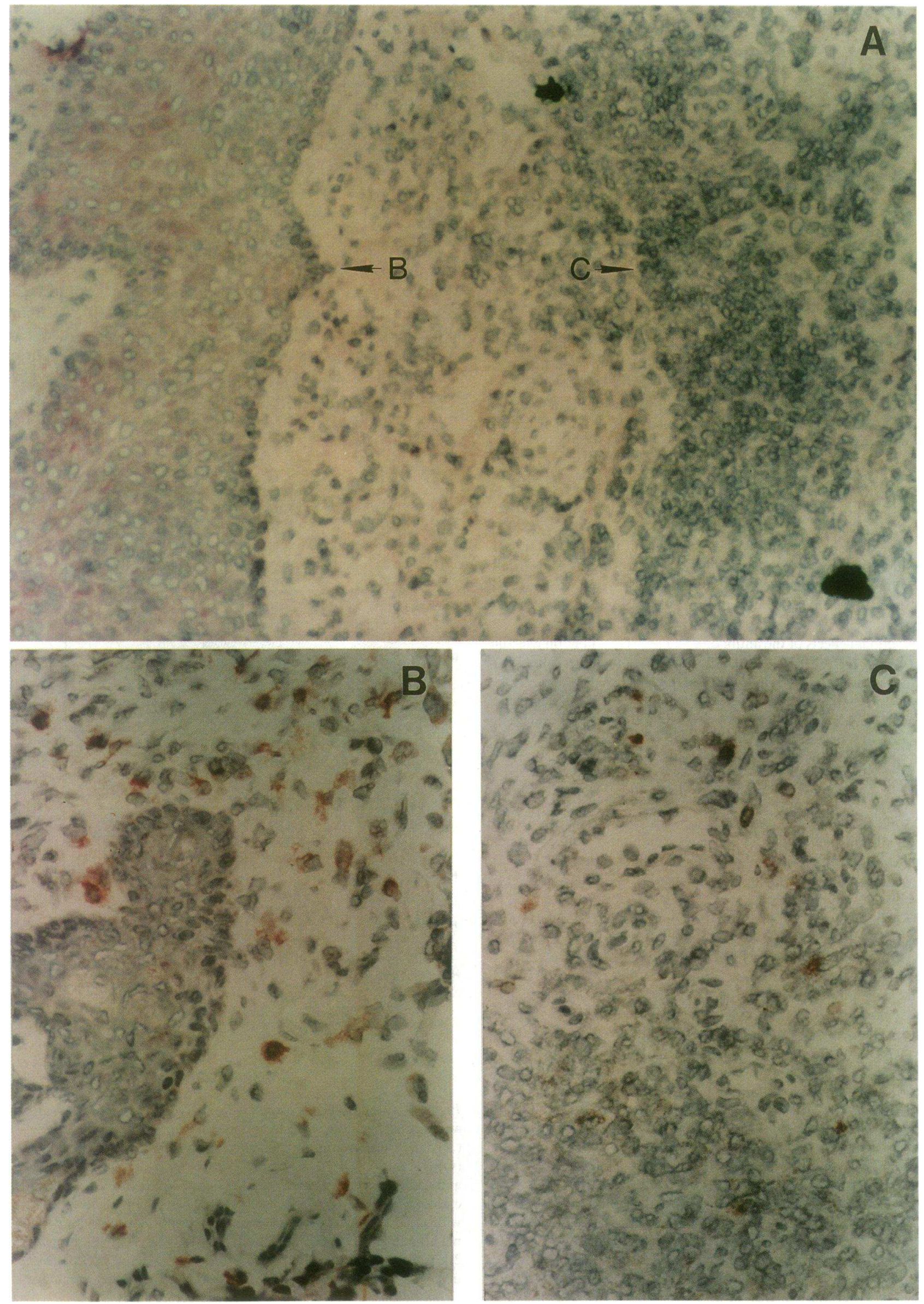
of previously described procedures (18). In particular, purified TA- $37^{+}$cells from peripheral blood of normal donors were shown to express $V \beta 16$ transcripts exclusively while displaying a highly polymorphic TCR $\mathrm{V} \alpha$ repertoire (data not shown). TA-37 mAb reacts with $2-4 \%$ of peripheral $\mathrm{CD}^{+}{ }^{+} \mathrm{T}$ lymphocytes in healthy individuals (data not shown).

As expected from previous studies (2), the IL-2-dependent TIL cell lines derived from the regressive lesion after stimulation with autologous tumor cells and/or autologous EBVtransformed B cells (EBV-B) were found to contain 1\% TA$37^{+}$cells (Fig. $1 \mathrm{~A}$ ). One of them was subjected to several cycles of purification with TA-37 (using immunomagnetic beads) and subsequent culture with IL-2. The cell line obtained after $10 \mathrm{~d}$ of additional expansion consisted of $88 \% \mathrm{~V} \beta 16^{+}$cells ( see Fig. $1 \mathrm{~B}$ ). The purity was eventually increased up to $98 \%$ $\mathrm{V} \beta 16^{+}$cells through a second round of immunomagnetic separation (Fig. $1 C$ ).

Flow cytometry analysis of this cell line showed a $\mathrm{CD} 2^{+}$, $\mathrm{CD}^{+}, \mathrm{CD}^{-}, \mathrm{CD}^{+}, \mathrm{CD}^{-} 6^{-}, \mathrm{TCR} \alpha / \beta^{+}, \mathrm{TCR} \gamma / \delta^{-}$phenotype (data not shown). TCR $V \alpha$ and $V \beta$ gene segment subfamilies expressed in the cells were analyzed after PCR amplification with a series of previously described TCR-V subfamilyspecific oligonucleotides (16). These $\mathrm{T}$ lymphocytes were found to express a unique $\mathrm{V} \beta$ subfamily, namely $\mathrm{V} \beta 16$, as well as a unique $\mathrm{V} \alpha 4$ gene segment (data not shown). Characterization of the $\mathrm{V} \beta 16$ transcripts showed the presence of a unique $\mathrm{V} \beta 16$-LRDSWN-J $\beta 2.1$ junctional sequence (Table I), corresponding to that found in 38 of 45 cDNA tested from the V $\beta 16$ mRNAs expressed in situ (1). Sequence analysis of the $\mathrm{V} \alpha 4$ gene segment also revealed the presence of a unique transcript with a V $\alpha$ 4-IPQGG-JGermd junctional sequence (Table I). Together, these data demonstrated that the cell line was made of a unique $\mathrm{V} \beta 16^{+} / \mathrm{V} \alpha 4^{+} \mathrm{T}$ lymphocyte, which does correspond to the clone selected and expanded at the tumor site.

Functional characterization of the $V \beta 16^{+}$TIL-derived T cell line. The $\mathrm{V} \beta 16^{+}$cells were tested in standard ${ }^{51} \mathrm{Cr}$ release assay against a panel of autologous and allogeneic target cells. As shown in Fig. 2, V $\beta 16$ cells displayed high levels of cytotoxicity ( $>70 \%$ specific lysis at an E/T ratio of 5:1) against the autologous melanoma cell line (M10) while failing to lyse other control targets including two allogeneic melanoma cell lines (M11, M12), autologous and allogeneic EBV-B cell lines, and the NK target K562. Blocking experiments indicated that the $\mathrm{V} \beta 16$ cells have the conventional profile of a HLA class I-restricted CTL. Fig. $3 A$ shows that cytotoxic activity is inhibited by anti-CD3, anti-CD8, anti-TCR $\alpha / \beta$, and anti-V $\beta 16$ $\mathrm{mAb}$ at the effector cell level and by W6/32 (anti-HLA class I monomorphic $\mathrm{mAb}$ ) at the target cell level. Furthermore, the presenting HLA class I molecule was characterized with a series of polyclonal antisera corresponding to the HLA phenotype of the patient (HLA-A3, -A10, -B14, -B35). As shown in Fig. 3 B, the anti-HLA-B14 serum was found to substantially reduce cytotoxicity as opposed to the other reagents. Note, that the other previously described clone with antitumor activity char- acterized in this experimental system was also restricted by HLA-B 14, although it expresses a distinct TCR (V $\beta 13, \mathrm{~V} \alpha 5$, or 15 , no homology with the $\mathrm{V} \beta 16$ transcript in the junctional sequence [2]).

Immunohistochemical analysis of the melanoma biopsy with an anti-V $\beta 16 \mathrm{mAb}$. Because we have previously demonstrated that the great majority of the $\mathrm{V} \beta 16$ sequences expressed in the tumor correspond to the unique V $\beta$ 16-LRDSWN-J $\beta 2.1$ CTL (1), here we could use the TA-37 mAb to directly visualize the potential antitumor reaction in the lesion. Immunohistochemical experiments (Fig. 4) revealed a substantial V $\beta 16^{+}$ CTL infiltrate in the peritumoral zone, including the papillary dermis (Fig. 4 B). Furthermore, V $\beta 16^{+}$lymphocytes were found directly in the lesion closely opposed to tumor cells (Fig. $4 C$ ). Such a distribution represents a common feature of regressive melanoma lesions (19).

\section{Discussion}

The concept of immunosurveillance (20) suggests that transformed cells express tumor-associated antigens that trigger an adaptive immune response aimed at rejection of the developing cancer lesions. This theory has proven extremely difficult to substantiate in the human. Perhaps one of the most relevant arguments is the increase of leukemic relapses in series of patients who have received $T$ cell-depleted bone marrow transplants (21). Regarding solid tumors, it is known that a minority of them, such as melanoma, renal cell carcinoma, or bladder cancer, display so-called "spontaneous" regressions and may respond $(22,23)$ to various types of immunotherapeutic approaches (e.g., BCG, interferons, IL-2, antiidiotypic antibodies). Yet, these observations constitute only indirect evidence, where actual mechanisms leading to tumor regression are largely unknown.

Malignant melanoma is the most studied model in the field of human tumor immunology. It is well known that the tumors are frequently infiltrated by $T$ lymphocytes, and attempts have been made to correlate the degree of these infiltrations with prognosis (24). In addition, multiple in vitro studies have shown that one can derive from either PBL or TIL IL-2-dependent $\mathrm{T}$ cell lines reactive against autologous melanoma cells (reviewed in reference 25). TIL-derived cell lines have even been reinfused to patients in the presence of IL-2 with occasional success (26). Recently, melanoma-associated antigenic peptides, such as those encoded by the MAGE genes, have been characterized and shown to be recognized by autologous CTL $(27,28)$. Yet, there is still no direct evidence that effective immune responses may occur physiologically in the course of tumor development. Demonstrating the existence of such antitumor reactions and characterizing their modalities is of critical importance in view of future therapeutic immunomodulation strategies aimed at complementing the conventional cancer treatments.

Figure 4. Immunohistological analysis of $\mathrm{V} \beta 16^{+}$TIL from a regressive melanoma. $(A)$ Hematoxylin-eosin staining of the tumor showing a general view of the tumoral and peritumoral area $(\times 100)$. ( $B$ and $C$ arrows) Those presented in $B$ and $C$ at higher magnifications $(\times 400)$. $(B$ and $C$ ) Selected representative sections of the regressive melanoma lesion stained with the anti-V $\beta 16 \mathrm{mAb}$ in the papillary dermis and in the dermal lesion, respectively $(\times 400)$. TA-37 mAb (anti-V $\beta 16)$ was used as 1:50 dilution. A polyclonal biotinylated sheep antibody to mouse Ig and a streptavidin-biotinylated peroxidase complex served as detection system for the primary antibody. 3-Amino-9-ethylcarbazole was used as a substrate for the enzyme. 
Our approach has been based on studying a potential local immune response when it is proven clinically and histologically that the tumor "spontaneously" regresses. In a first step (1), it was found that the selected model lesion is indeed infiltrated by $\mathrm{T}$ lymphocytes and that some of these TILs represent in situ amplified clonal cell populations. We show here that the major infiltrating clone is a conventional CTL. It has not been established whether this V $\beta 16$ CTL is indeed "tumor specific." It is, however, clear that the antitumor activity is selective because both autologous PHA blasts (data not shown) and autologous EBV-B cells (the only available nontumoral cell types from the patient) are not lysed. Further studies aimed at identifying the antigenic peptide(s) that determine(s) the recognizition of melanoma cells will clarify this issue. In any case, the present data constitute to our knowledge the first direct evidence that CTL, able to destroy tumor cells, are selected in situ, clonally amplified, and are in a physical situation appropriate to contribute to tumor regression in a clinically relevant (i.e., "spontaneously" regressive) case of a human cancer. These results strongly support the view that the immune system may indeed operate according to the immunosurveillance concept.

\section{Acknowledgments}

We thank Dr. M. F. Avril for providing patient materials used in this study, S. Robache for her help in preparing the V $\beta 16$ construct, and Dr. F. Faure for advice and discussion. The excellent technical assistance of M. Talbot, I. Billaud, L. Pilatre, and V. Morand is greatfully acknowledged.

This work was supported by Association pour le Recherche contre le Cancer grant 6338. A. Mackensen is a recipient of a fellowship from the Deutsche Forschungsgemeinschaft (Ma 1351/1-1).

\section{References}

1. Ferradini, L., A. Mackensen, C. Genevee, J. Bosq, P. Duvillard, M. F. Avril, and T. Hercend. 1993. Analysis of $T$ cell receptor variability in tumor-infiltrating lymphocytes from a human regressive melanoma. J. Clin. Invest. 91:1183-1190.

2. Mackensen, A., L. Ferradini, G. Carcelain, F. Triebel, F. Faure, S. Viel, and T. Hercend. 1993. Evidence for in situ amplification of cytotoxic T-lymphocytes with antitumor activity in a human regressive melanoma. Cancer Res. 53:35693574.

3. Leo, O., M. Foo, D. H. Sachs, L. E. Samelson, and J. A. Bluestone. 1987. Identification of a monoclonal antibody specific for a murine $\mathrm{T} 3$ polypeptide. Proc. Natl. Acad. Sci. USA. 84:1374-1378.

4. Lanier, L. L., J. J. Ruitenberg, J. P. Allison, and A. Weiss. 1987. Biochemical and flow cytometric analysis of CD3 and Ti expression on normal and malignant T cells. In Leukocyte Typing III. A. J. McMichael, editor. Oxford University Press, Oxford, UK. 175-178.

5. Band, H., F. Hochstenbach, J. McLean, S. Hata, M. S. Krangel, and M. B. Brenner. 1987. Immunochemical proof that a novel rearranging gene encodes the T cell receptor delta subunit. Science (Wash. DC). 238:682-684.

6. Brodsky, F. M., and P. Parham. 1982. Monomorphic anti-HLA-A, B, C monoclonal antibodies detecting molecular subunits and combinatorial determinants. J. Immunol. 128:129-135.

7. Hercend, T., E. L. Reinherz, S. Meuer, S. F. Schlossman, and J. Ritz. 1983 Phenotypic and functional heterogeneity of human cloned natural killer cell lines. Nature (Lond.). 301:158-160.

8. Romagné, F., L. Besnardeau, and B. Malissen. 1992. A versatile method to produce antibodies to human $T$ cell receptor Vbeta segments: frequency determination of human Vbeta2 $+T$ cells that react with toxic-shock syndrome toxin-1. Eur. J. Immunol. 22:2749-2752.
9. Kozak, M. 1984. Compilation and analysis of sequences upstream from the translational start site in eukaryotic mRNAs. Nucleic Acids Res. 12:857-872.

10. Takebe, Y., M. Seiki, J. I. Fujisawa, P. Hoy, K. Yokota, K. I. Arai, M. Yoshida, and N. Arai. 1988. SRalpha promoter: an efficient and versatile mammalian cDNA expression system composed of the simian virus 40 early promoter and the R-U5 segment of human T-cell leukemia virus type 1 long terminal repeat. Mol. Cell. Biol. 8:466-472.

11. Letourneur, F., and B. Malissen. 1989. Derivation of a T cell hybridoma variant deprived of functional $\mathrm{T}$ cell receptor alpha and beta chain transcripts reveals a nonfunctional alpha-mRNA of BW5147 origin. Eur. J. Immunol. 19:2269-2274.

12. Wegener, A. M. K., F. Letourneur, A. Hoeveler, T. Brocker, F. Luton, and B. Malissen. 1992. The T cell receptor/CD3 complex is composed of at least two autonomous transduction modules. Cell. 68:83-95.

13. Malissen, B., N. Rebai, A. Liabeuf, and C. Mawas. 1982. Human cytotoxic T cell structures associated with expression of cytolysis. I. Analysis at the clonal cell level of the cytolysis-inhibiting effect of 7 monoclonal antibodies. Eur. J. Immunol. 12:739-747.

14. Kearney, J. F., A. Radbruch, B. Liesegang, and K. Rajewsky. 1979. A new mouse myeloma cell line that has lost immunoglobulin expression but permits the construction of antibody-secreting hybrid cell lines. J. Immunol. 123:15481550 .

15. Belyavsky, A., T. Vinogradova, and K. Rajewsky. 1989. PCR-based cDNA library construction: general cDNA libraries at the level of a few cells. Nucleic Acids Res. 17:2919-2932.

16. Genevee, C., A. Diu, J. Nierat, A. Caignard, P. Y. Dietrich, L. Ferradini, S. Roman-Roman, F. Triebel, and T. Hercend. 1992. An experimentally validated panel of sub-family-specific oligonucleotide primers (Valphal-w29/Vbetal-w24) for the study of human $\mathrm{T}$ cell receptor variable $\mathrm{V}$ gene segment usage by polymerase chain reaction. Eur. J. Immunol. 22:1261-1269.

17. Holton, T. A., and M. W. Graham. 1990. A simple and efficient method for direct cloning of PCR products using ddT-tailed vectors. Nucleic Acids Res. 19:1156.

18. Diu, A., F. Romagne, C. Genevee, C. Rocher, J. M. Bruneau, A. David, F. Praz, and T. Hercend. 1993. Fine specificity of monoclonal antibodies directed at human $\mathrm{T}$ cell receptor variable regions: comparison with oligonucleotide-driven amplification for evaluation of Vbeta expression. Eur. J. Immunol. 23:14221429.

19. Barnhill, R. L., and M. C. Mihm. 1993. The histopathology of cutaneous malignant melanoma. Semin. Diagn. Pathol. 10:47-75.

20. F. M. Burnet. 1970. The concept of immunological surveillance. Prog. Exp. Tumor Res. 13:1-27.

21. Horowitz, M. M., R. P. Gale, P. M. Sondel, J. M. Goldman, J. Kersey, H. J. Kolb, A. A. Rimm, O. Ringden, C. Rozman, B. Speck, R. L. Truitt, F. E. Zwaan, and M. M. Bortin. 1990. Graft-versus-leukemia reactions after bone marrow transplantation. Blood 75:555-562.

22. Lotze, M. T., J. T. Rubin, and H. J. Zeh. 1992. New biological agents come to bat for cancer therapy. Curr. Opin. Oncol. 4:1116-1123.

23. Mittelmann, A., Z. J. Chen, H. Yang, G. Y. Wong, and S. Ferrone. 1992. Human high molecular weight melanoma-associated antigen (HMW-AA) mimcry by mouse anti-idiotypic monoclonal antibody MK2-23: induction of humoral anti-HMW-MAA immunity and prolongation of survival in patients with stage IV melanoma. Proc. Natl. Acad. Sci. USA. 89:466-470.

24. Poppema, S., E. B. Brocker, L. De Leij, D. Terbrack, T. Visscher, A. Ter Haar, E. Macher, T. H. The, and C. Sorg. 1987. In situ analysis of the mononuclear cell infiltrate in primary malignant melanoma of the skin. Clin. Exp. Immunol. 51:77-82.

25. C. D. Platsoucas. 1991. Human autologous tumor-specific T cells in malignant melanoma. Cancer Metastasis Rev. 10:151-176.

26. Rosenberg, S. A., B. S. Packard, P. M. Aebersold, D. Solomon, S. L. Topalian, S. T. Toy, P. Simon, M. T. Lotze, J. C. Yang, C. A. Seip, C. Simpson, C. Carter, S. Bock, D. Schwartzentruber, J. P. Wei, and D. E. White. 1988. Use of tumor-infiltrating lymphocytes and interleukin-2 in the immunotherapy of patients with metastatic melanoma. $N$. Engl. J. Med. 319:1676-1680.

27. Van der Bruggen, P., C. Traversari, P. Chomez, C. Lurquin, E. de Plaen, B. van den Eynde, A. Knuth, and T. Boon. 1991. A gene encoding an antigen recognized by cytolytic $\mathrm{T}$ lymphocytes on a human melanoma. Science (Wash. DC). 254:1643-1647.

28. Traversari, C., P. Van der Bruggen, I. F. Luescher, C. Lurquin, P. Chomez, A. Van Pel, E. De Plaen, A. Amar-Costesec, and T. Boon. 1992. A nonapeptide encoded by human gene MAGE-1 is recognized on HLA-A1 by cytolytic T lymphocytes directed against tumor antigen MZ2-E. J. Exp. Med. 176:14531457. 